\title{
EL PAPEL DEL MOVIMIENTO JARANERO EN LA SALVAGUARDA DEL FANDANGO JAROCHO (MÉXICO)
}

\section{THE ROLE OF THE JARANERO MOVEMENT IN THE SAFEGUARDING OF FANDANGO JAROCHO (MEXICO)}

\author{
Melba Alí Velázquez Mabarak Sonderegger ${ }^{1}$ \\ Giane da Silva Mariano Lessa ${ }^{2}$ \\ Universidade Federal da Integração Latino-Americana, Brasil
}

Resumen El fandango jarocho es un evento festivo comunitario con música y baile, producto del mestizaje, cuya tradición hunde sus raíces desde la época colonial. Durante la primera mitad del siglo XX, el fandango jarocho atravesó un punto crítico para la continuación de su práctica, por lo que, a partir de la década de los 80 , surge un colectivo interesado en su investigación, revitalización y difusión, denominado Movimiento jaranero. En estas páginas se explicita el proceso de salvaguarda del fandango jarocho iniciado por el Movimiento jaranero, entendido como una articulación socio-estatal, que buscó garantizar una generación de relevo y la pervivencia del fandango. Como resultado de la tensión entre pasado y presente, actualmente el fandango y el son jarocho - el género musical que le hace parte - se manifiestan en diversas esferas y con variaciones que alcanzan incluso la fusión con otros géneros musicales.

Palabras clave: Fandango jarocho, Salvaguarda, Patrimonialización, Culturas populares.

Abstract: Fandango jarocho is a festive community event including music and dancing, born out of the blending of cultures, with roots that run as deep as the colonial era. For the first half of the $20^{\text {th }}$ century, the continued practice of the fandango jarocho went through difficult times, and it was not until the eighties that a collective known as Movimiento Jaranero emerged with an interest in its investigation, dissemination and revitalization. The following pages detail the safeguarding process carried out by the mentioned collective, analyzing it as an articulation of society and state for the purpose of guaranteeing the fandango survival through a new generation that would take it over. Currently, as a result of the tension between past and present, both the fandango and the son jarocho (which is the musical genre that sustains the practice) have found expressions in various scenes, presenting variations that even encompass fusion with other musical genres.

Keywords: Fandango jarocho, fandango caiçara, safeguarding, patrimonialization, popular cultures.

\footnotetext{
${ }^{1}$ Egresada del Programa de Posgraduação Interdisciplinar em Estudos Latino-Americanos de la Universidade Federal da Integração Latino-Americana. Licenciada en Lengua y Literatura Hispánicas por la Universidad Veracruzana. Email: melba_sonderegger@hotmail.com

2 Doctora en Memória Social por la Universidade Federal do Estado do Rio de Janeiro. Profesora adjunta de la Universidade Federal da Integração Latino-Americana.
} 


\section{EL FANDANGO EN MÉXICO}

Señores, qué son es este

Señores, el fandanguito la primera vez que lo oigo válgame dios qué bonito.

-El fandanguito, son jarocho

El término fandango posee múltiples acepciones que varían según la región desde la que se enuncia; su etimología, incluso, es resbaladiza. El término no encuentra definición clara de sus orígenes autorales, espaciales y temporales, generando polémica entre los investigadores que intentan arrojar luces sobre su génesis. Para Antonio García de León, la palabra deriva del kimbundu fanda, que significa fiesta o convite, al que se le agregó el sufijo hispano - ango, de tono despectivo (GARCÍA, 2006, p. 27). Esta probable raíz de la lengua angolana se explica a la luz del comercio de esclavos africanos con dirección al Nuevo Mundo en los siglos XVI y XVII, preponderantemente hombres y mujeres capturados en el África bantú (NGOU-MVE, 1994).

Respecto al origen del fandango como género bailable y musical, muchas hipótesis han surgido para aclarar la cuestión. Núñez señala que el fandango "fue traído [a América] por los españoles, más bien por los andaluces que tanto lo usaban antiguamente" (NÚÑEZ, 1932, p. 187). Por otro lado, Pereira afirma que "[...] considerar os fandangos como expressão cultural ibérica é um engano. Os estudiosos da cultura popular europeia localizam a origem dos fandangos na América Latina, inclusive daquela modalidade que se tornou uma tradição espanhola" (PEREIRA, apud FERRERO, 2006, p. 317). Otro historiador que concuerda con esta idea es Peter Burke, quien registró que “o fandango veio da América para a Espanha por volta de 1700” (BRITO, apud FERRERO, 2006, p. 317).

$\mathrm{Si}$, como estos investigadores apuntan, el fandango surgió por primera vez en las colonias americanas, habría emergido como resultado de la llegada de los colonizadores iberos, herederos a su vez de miscigenaciones culturales árabes, andaluzas, napolitanas, canarias y portuguesas, y en el crisol del nuevo continente se habría mezclado con elementos de la cultura indígena y africana, dando origen a variantes de fandangos que evolucionaron a través de sus propios procesos en los países latinoamericanos, desde la implantación de las colonias, la formación de los Estados 
nación y sus respectivas influencias culturales. Los instrumentos, las danzas, el estilo de tocar y las músicas que surgirían a partir de las mezclas de estas variables se volvieron bastante populares en las colonias americanas y, probablemente durante el siglo XVIII habrían de exportarse de vuelta a tierras ibéricas, generando a su vez, las variantes de fandango que existen actualmente en España y Portugal.

En México, el término fandango alude a una fiesta con música y baile zapateado realizada alrededor de una tarima, cuya práctica producto del mestizaje hispánico, indígena y africano, hunde sus raíces desde la época colonial. Esta definición no sólo comprende el aspecto musical y dancístico, sino también una manifestación que engloba identidades, memorias sociales, el ingenio de un pueblo y una cosmovisión codificada en los versos, la danza, los códigos de conducta y la colectividad (GOTTFRIED, 2013; PITRE, 2016).

Formalmente de denomina fandango ${ }^{3}$ al universo socio-espacial donde se representa alguna de las múltiples variedades de sones: jarocho, huasteco, arribeños, abajeños, tixtlecos, itsmeños, etcétera, dependiendo de la zona geográfica a la que se atienda. Se entienden como sones a los géneros lírico-coreográficos interpretados típicamente por la población mestiza de las costas y tierra adentro (SEVILLA, 2013; SÁNCHEZ, 2002). Este trabajo se enfoca particularmente en el fandango jarocho, entendido como universo socio-festivo comunitario en donde se integran el zapateado (danza sobre tarima de madera que funge como percusión) y el son jarocho (género musical propio del fandango jarocho), que comprende, a su vez, el aspecto lírico y el musical. El son jarocho se toca en una amplia región del estado de Veracruz, que abarca la zona del puerto y sus alrededores, la Cuenca del Papaloapan, la región de Los Tuxtlas y la de Coatzacoalcos y Minatitlán, hasta sus límites con los estados de Oaxaca y Tabasco (SÁNCHEZ, 2002). Se identifica tradicionalmente en la región de la llanura costera del centro-sur del estado de Veracruz, en la parte central de Golfo de México. Específicamente, comprende "la franja territorial que va del municipio de Minatitlán, en el sur del Estado, hasta el municipio de Boca del Río, en la parte central de la entidad" (STANFORD, 1984, p. 47). Sin embargo, es pertinente señalar que actualmente esta manifestación cultural ha desbordado estas fronteras "originales" para hacer presencia en otras regiones de Veracruz, así como en diversos estados del país -como Oaxaca,

\footnotetext{
${ }^{3}$ En algunas regiones como la Huasteca, el fandango también es llamado "huapango", palabra derivada del náhuatl
} "cuauhpanco", que significa "sobre la tarima de madera" (GARCÍA, 2006). 
Tabasco y la Ciudad de México-e incluso en el extranjero, principalmente en los Estados Unidos de América, gracias a los trabajadores migrantes que llevaron el son jarocho a ese país (FIGUEROA, 2007; KOLH, 2007).

Los fandangos jarochos suelen variar, según las particularidades de cada microrregión. Pero las diferencias de estilo van más allá de las localidades y responden a las preferencias de cada grupo de fandangueros. Los versos de un son pueden variar de un pueblo a otro, de fandango a fandango, mediando apenas unos kilómetros de por medio, tanto como puede variar el repertorio de un versador con cualquier otro. Las afinaciones de los instrumentos, la velocidad del rasgueo, el modo de zapatear, son tan sólo algunas de las características estilísticas que pueden diferir. Pese a todo, debido a que la improvisación es uno de los elementos característicos de este género festivo-musical, un fandango nunca resulta igual a otro.

No obstante las variaciones, pueden advertirse algunos elementos constantes que caracterizan a esta manifestación cultural. Como se ha mencionado líneas arriba, se trata de un evento festivo, generalmente acompañado de comida y bebida harta, en el que asisten jóvenes y viejos, hombres y mujeres, legos y experimentados. Las personas se sitúan en torno a una tarima de madera elevada del suelo, en el que se realiza el zapateado. La tarima y sus bailadores son un instrumento más del fandango. Otros instrumentos musicales que tradicionalmente se encuentran en el son jarocho son: la jarana, instrumento de cuerdas que lleva la armonía mediante rasgueos y cuya presencia es predominante en el son jarocho; el requinto (también llamado guitarra de son), un cardófono que realiza la declaración del son, es decir, que indica al resto de los músicos el son que se tocará, el tono, así como el ritmo y velocidad; la quijada, que es una mandíbula seca de equino a la que se le hace vibrar con pequeños golpes acompasados y también se la raspa con un palito, para hacer sonar los dientes; el arpa; el pandero y el violín (FIGUEROA, 2007; KOHL, 2007). Menos frecuentes, pero que también pueden ser utilizados en el son jarocho son el marimbol, una caja de resonancia con lengüetas de metal; y el cajón peruano, que acompaña en la percusión.

Para García de León (2006), los primeros fandangos que pueden ser considerados como propiamente jarochos surgieron desde mediados del siglo XVIII, en una época en donde las regiones del país comenzaban a consolidarse. Pero fue un siglo después, durante la construcción del México independiente, que los fandangos adquirieron una dimensión que esbozaba un aire 
nacionalista, pues "sirvieron como afirmación de lo propio - lo mestizo o lo criollo -, frente al rechazo de lo extranjero - lo gachupín - [... La música que se tocaba en aquellas fiestas de principios del siglo XIX [...] sirvió como argumento fuerte a la hora de reconocer 'lo mexicano"” (PÉREZ, 1994, p. 82). Así, los fandangos, con su música y baile asociados, comenzaban a perfilarse como símbolo identitario para algunas regiones y, por extensión, del país.

Si nos atenemos a la literatura colonial - sobre todo la censuradora del Santo Oficio - los fandangos en la Nueva España vivieron su edad de oro en el siglo XVIII y en el México independiente del siglo XIX. Inclusive Pérez Montfort hace especial hincapié en el auge de los fandangos jarochos durante la segunda mitad del siglo XIX debido a la prosperidad económica experimentada en las tierras bajas del Sotavento Veracruzano, particularmente en la localidad de Tlacotalpan, a orillas del río Papaloapan, centro del comercio fluvial (PÉREZ, 1991). Sin embargo, el siglo XX trajo consigo el declive económico y cultural de este escenario jarocho. Como resultado de la desaceleración de las actividades económicas de la región el furor de las fiestas jarochas parece difuminarse. Pero sin duda, el factor de fuerza mayor que convulsionó las formas de vida tradicionales fue la Revolución Mexicana de 1910 en contra de la dictadura de Porfirio Díaz, lo que en términos locales produjo constantes levantamientos campesinos en Veracruz.

Esta situación habría de mudar en los albores del México posrevolucionario, cuando se generó un proyecto de Estado para crear, rescatar o resignificar imágenes que representaran la identidad mexicana -elementos culturales, históricos, políticos y sociales-, con el propósito de producir una narrativa unificada del territorio y arraigar las semillas del nacionalismo para la revalorización de las culturas, las cuales, no obstante, debieron acoplarse a las necesidades de la época: el son jarocho se popularizó en la urbe y comenzó a aparecer en medios de comunicación (cine, radio, televisión), mientras que el fandango, en el entorno rural, se realizaba cada vez menos. Poco a poco, la tarima es sustituida por el escenario y el son es desasociado de su fiesta. El periodo de transición del ámbito rural a los espacios urbanos permitió la profesionalización del son jarocho y la conformación de grupos de soneros cuyos integrantes, provenientes del interior de Veracruz, se establecieron en las ciudades en busca de empleo o por estudio. Estos músicos del son habrán de actualizar el género para adecuar la estructura libre del son en el fandango en categorías musicales más pertinentes para los oídos del nuevo público. Con el auge de músicos de son jarocho como Lino Chávez o Andrés Huesca, el repertorio de sones se limitó apenas a aquellos más 
populares y el ingenio espontáneo característico del género fue soslayado por la repetición de versos fijos que podían ser ensayados por la agrupación como canciones con letra definida, y a una velocidad y virtuosismo mayor que en el fandango.

\section{EL MOVIMIENTO JARANERO}

Yo me encontré un cascabel que ya se estaba muriendo una soga le compré andaba desfalleciendo de la muerte lo salvé por eso me anda siguiendo.

-El cascabel, son jarocho

Hablar sobre el Movimiento jaranero es entrar en arenas movedizas: las fuentes se contradicen y es imposible encontrar consenso en relación a las fechas y los datos. Entra aquí la cualidad contradictoria y complementar de la memoria social - o mejor dicho, las memorias, porque son múltiples. Algunas personalidades consideradas integrantes del Movimiento reniegan de él, desde los que cuestionan la nomenclatura hasta los que simplemente no quieren ser considerados parte del Movimiento, y tampoco es fácil distinguir con claridad a quiénes fueron los miembros fundadores, en tanto el Movimiento realizó un trabajo que fue caminando conforme a la marcha. Lo que sí puede enumerarse son los acontecimientos (y aquellos que participaron en ellos) que abrevaron a lo largo de los años en lo que hoy aún se mueve.

La fecha que, para algunos investigadores, marcó el nacimiento del Movimiento jaranero fue 1977, con la fundación del grupo Mono Blanco. Los miembros originales del grupo fueron los jóvenes Gilberto Gutiérrez Silva y su hermano José Ángel, originarios del sur de Veracruz y radicados en la Ciudad de México, quienes convidaron a integrarse al grupo a Juan Pascoe, nacido en Estados Unidos pero radicado también en la capital mexicana. Estos tres jóvenes músicos comenzaron sus planes para tocar el son jarocho tradicional y no la versión comercial que se escuchaba en la radio, investigar las antiguas fiestas comunitarias y organizar nuevamente los fandangos, que ya eran casi imposibles de encontrar. Poco después, Andrés Vega y su requinto 
también harían parte de la agrupación. Es importante resaltar que su postura de salvaguarda del son y del fandango entendía que para rescatar la tradición había que renovarla (FIGUEROA, 2007).

Con ayuda de Arcadio Hidalgo, entonces ya un jaranero y versador experimentado que también habría de integrarse al grupo, los músicos de Mono Blanco acudieron a las poblaciones en donde aún se practicaban fandangos, como en Saltabarranca, Tlacotalpan o Minantitlán (SEVILLA, 2017). Su principal motivación era aprender el son jarocho de los viejos campesinos, el son que era inclusive discriminado por no parecerse a la versión vertiginosa y preciosista que se escuchaba en la radio y los discos de acetato. Pronto descubrirían que para asegurar que la tradición del fandango continuara había que crear generaciones de relevo.

Los Monos, en su labor de revivificación del son, fungieron también como promotores culturales, al entablar enlaces entre la organización de fandangos y eventos relacionados con el son jarocho y diversas instituciones locales y estatales. Gilberto Gutiérrez consiguió el apoyo de la Secretaría de Educación Pública para financiar la realización de fandangos dentro y fuera de Veracruz (ÁVILA, 2008). Con los fandangos de nuevo en las plazas los viejos soneros arribaban de todos lados para departir su conocimiento, y los jóvenes interesados comenzaron el contacto con la música y la fiesta. En la década de los noventa Gilberto Gutiérrez y su grupo Mono Blanco le proponen a Promoción Cultural de la Secretaría de Educación Pública (antecedente del Conaculta) un proyecto llamado Promoción y Difusión del Son Jarocho a partir del Fandango. Este proyecto incluía la realización de fandangos durante las festividades patronales de algunos municipios, pero desde el inicio Mono Blanco percibió que los jóvenes que llegaban a los fandangos poco sabían de la dinámica de la fiesta. A pesar del interés y disposición por participar, faltaba la técnica. Para solventar esta carencia se comenzaron a realizar talleres, primero de zapateado y luego del resto de los elementos del fandango con ayuda de las familias Vega y Utrera (GUTIÉRREZ, 2009). Los talleres que enseñaban a los jóvenes a fabricar los instrumentos; la estructura y temática de los sones para poder cantar e improvisar; la forma de afinar y tocar la jarana y el requinto, etc., fueron los puentes entre las viejas y las nuevas generaciones para restaurar la vigencia del fandango como el eje central del género.

Con apoyo del IVEC se realizaron campamentos para jóvenes en donde se les enseñaba algunos principios sobre la estructura rítmica y armónica de los sones, las formas líricas del versado, afinaciones y rasgueo de la jarana, la leona, arpa y otros instrumentos musicales del 
fandango, etc. Durante esa década se realizaron diez ediciones del campamento en comunidades como el Hato, Pajapan, Jáltipan, y los participantes eran jóvenes provenientes de diversos lugares, tanto de comunidades indígenas popolucas y nahuas, muchachos de las ciudades e incluso algunos adolescentes chicanos, que viajaban a México para aprender a tocar son jarocho y retomar sus raíces culturales en los fandangos (FANDANGO, 2006).

Figuras como Juan Meléndez de la Cruz, de Minatitlán, Veracruz, ha sido otro de los miembros activos del Movimiento jaranero. Estudió en la Ciudad de México, pero al volver a su tierra natal comenzó como promotor cultural con talleres y campamentos de son jarocho para niños, y gracias a su organización se realizó el primer fandango de la era moderna en Minatitlán, en 1984. Junto con Arcadio Hidalgo, Antonio García de León y los hermanos Noé y Benito González fundaron el grupo Tacoteno, en 1984, y juntos rescataron sones poco conocidos en ese entonces, como Los chiles verdes o Las limas. Juan Meléndez solía anotar los versos que escuchaba ahí donde iba, y para 2004 publicó dicha recopilación de lírica en el libro Versos para más de 100 sones jarochos, texto bastante recurrido para aquellos que quieren aprender la versada (FORMATO SIETE, 2017).

Otro de los defensores de la "tradición vieja" en la región de los Tuxtlas fue Juan Pólito Baxin. Él aprendió de su familia la forma tradicional y pausada de tocar la media guitarra de son, y se mantuvo fiel a su estilo tuxtleco al formar parte del ensamble Cultivadores del Son, fundado en 1987 junto con Andrés Moreno, José Luis Constantino y Daniel Hernández, y posteriormente también Juan Mixtega Baxin. Al inicio, Juan Pólito y los Cultivadores del Son tocaban apenas en comunidades cercanas a la región, pues sus integrantes debían ocuparse de sus actividades en el campo, pero tiempo después, inspirados por el éxito del grupo Mono Blanco, entraron de lleno a la actividad musical con el son jarocho (KOHL, 2007). En su trayectoria fungieron también como promotores culturales, al impartir talleres de jarana, guitarra de son, laudería y zapateado en la Casa de la Cultura de San Andrés Tuxtla (OLIVARES, 2016). A Juan Pólito se le atribuye el rescate de sones antiguos como El zopilote, El sapo, El torero o El capotín, gracias al contacto directo con los ancianos de la región, que mantenían en la memoria los versos y los sones (FIGUEROA, 2007).

Otra figura importante en la reivindicación del son jarocho es Antonio García de León, un formidable lingüista, antropólogo, historiador y miembro del grupo Zacamandú, aunque también 
ha colaborado para otros grupos como Tacoteno, Los Utrera, Son de Madera y Los Cojolites. Ha realizado diversos estudios en relación a la historia social, económica y cultural del país, y entre sus trabajos se encuentran investigaciones sobre fandango y el son jarocho. Por esos méritos en su carrera ha merecido el Premio Nacional de Ciencias y Artes (2015). La agrupación Zacamandú, formada en 1979 y desintegrada en 1995, recopiló sones jarochos olvidados y los materializó en un disco memorable titulado Antiguos sones jarochos.

A menudo, los hijos o nietos de los antiguos fandangueros se integraron al movimiento y en ese proceso el son jarocho comenzó a reinventarse; de los antiguos se rescataba la lírica de los sones desconocidos y de los practicantes jóvenes surgían nuevos versos para los viejos sones. Así es como diversos miembros de las familias, descendientes de los músicos de los grupos pioneros en el Movimiento, continúan con la labor iniciada por sus antepasados. Algunas de estas agrupaciones han sumado más de treinta años mudando a sus integrantes y heredando el gusto por el son jarocho y su fiesta.

Además de Mono Blanco, Tacoteno, Cultivadores del Son y Zacamandú se constituyeron nuevos grupos jaraneros que compartían la consciencia colectiva de revitalizar los fandangos, como Chuchumbé, Los Parientes, Río Crecido, Los Utrera, Son de Madera, La Plaga, Siquisirí, Los Indios Verdes, etc. (HERNÁNDEZ, 2016). Lo que une a estas agrupaciones es el afán de resistencia al son jarocho de folclor nacional al que consideran una deformación del son campesino, por ello se empeñan por contrarrestar con la ejecución de la manera tradicional. Sumados a los integrantes de estas agrupaciones, también han participado en la labor de salvaguarda del fandango y su música muchos otros miembros de la sociedad civil, individuos que han trabajado voluntariamente como promotores culturales para conseguir apoyos y patrocinios en la elaboración de las actividades del Movimiento, investigadores y académicos que han procurado rescatar elementos tradicionales casi olvidados; periodistas, locutores y otros entes de los medios de comunicación y difusión que han hecho eco del valor del género musical. Es por ello que la trayectoria del Movimiento jaranero se entiende como un entramado socio-estatal, protagonizado por miembros de la sociedad civil (músicos, lauderos, versadores, bailadores, investigadores, etc.) en pugna por difundir el son jarocho y revitalizar el fandango, con patrocinio, apoyo y difusión de diversas instituciones culturales, asociaciones privadas, organizaciones gubernamentales y académicas, así como con la colaboración de promotores culturales civiles y estatales que 
fungieron como mediadores entre los integrantes del Movimiento jaranero y el Estado -a menudo los mismos músicos pasaron al servicio público- para gestionar recursos públicos en la realización de talleres, fandangos, festivales, encuentros de jaraneros, conferencias, etc.

Los múltiples actores (tanto societales como estatales) que han intervenido en el fomento y la revitalización del son han perseguido intereses diversos y con consecuencias visibles al día de hoy. Entre estos actores se puede identificar a grupos regionales que enseñan, tocan son jarocho y hacen fandangos con un propósito comunitario; otros grupos que recuperan el son jarocho para fusionarlo con géneros modernos; otros que encuentran en el son jarocho un nicho laboral, etc.; y, por otro lado, el Estado que retoma el símbolo y popularidad del género y la práctica como bandera de la identidad cultural y estrategia de unificación nacional. Las posiciones antes mencionadas no son excluyentes y más bien se pueden combinar diversos intereses en los mismos actores, por ejemplo: un grupo de soneros que hacen comunidad en el fandango pueden ejercer la música como actividad profesional recibiendo remuneración por su trabajo, así como perseguir la idea del son como patrimonio cultural de los veracruzanos y mexicanos.

\section{ALCANCES DEL MOVIMIENTO JARANERO}

\section{Tuve que volverme río para escaparme del mar sin poder imaginar que el mar es destino mío. \\ -El Balajú, son jarocho.}

Como se ha mencionado líneas arriba, el Movimiento jaranero intentaba contrarrestar la idea instaurada en los medios de comunicación y en el imaginario popular de que el son jarocho era aquella estampa folklórica que se corporeizaba en músicos de uniforme blanco con paliacate al cuello que tocaban a ritmo vertiginoso y sazonaban las canciones con décimas maliciosas. Es por ello que la música producida por los músicos del Movimiento se distinguió por oposición al son comercial. Para Cardona y Rinaudo (2017), el Movimiento jaranero simbolizó también una postura de resistencia contra el proceso de blanqueamiento que esta práctica afromexicana originaria del sur de Veracruz demostró en los años posrevolucionarios. Para estos investigadores, el son jarocho, detentado originalmente por población de marcado origen afroindígena, sufrió transformaciones en su representación durante las décadas de 1930 y 1940 para encarnar a un 
jarocho estereotipado y blanqueado que figura en películas y ballets folclóricos y que reafirma lo blanco y omite lo que de negro e indígena le debe. El Movimiento jaranero, entonces, surgió como oposición a la elitización de la cultura jarocha que ahogaba las otras herencias étnicas, y en una labor de "desblanqueamiento" se reflexiona sobre el pasado indígena y, para algunos jaraneros, comienza una reivindicación de la raíz negra, por lo que algunos han denominado al son jarocho como "música de resistencia afromexicana" (DÍAZ-SÁNCHEZ; HÉRNÁNDEZ, 2013 apud CARDONA; RINAUDO, 2017).

La defensa de lo tradicional por parte del Movimiento jaranero incidió también en la valorización de la lírica del son jarocho. En contraste con las versadas comúnmente expresadas a inicios del siglo XX por conjuntos jarochos en la urbe -generalmente en bares, marisquerías, clubes nocturnos o salones de baile- que se caracterizaban por contener versos irreverentes o "picantes" para solaz del público, las agrupaciones del Movimiento defendían que el son jarocho era más que versos chabacanos. Para ellos, la poética de los sones podía ser también comparable con la mejor tradición del siglo de oro español o del barroco novohispano, por lo que era tan necesario su rescate y valorización (GARCÍA, 2006; ALCÁNTARA, 2017).

El proceso de revivificación de la lírica del son jarocho puede entenderse en dos vertientes que se sucedieron, sin excluirse. La primera etapa implicó el rescate de la memoria social a través de la entonación de los versos de los antiguos sones, considerados "auténticos", y que narraban mitos, el cotidiano y eventos del pasado -los llamados "versos sabidos"-, que a fuerza de repetirse de fandango en fandango pertenecen al imaginario popular (MELÉNDEZ, 2016). La segunda etapa surgió con el entendimiento de que la lírica del son jarocho no podía ser siempre una mímesis de sí misma y que para mantenerse viva debía recrearse; por ello se buscaba que la nueva generación de jaraneros no sólo memorizara y entonara versos antiguos sino que también aprendiera de las estructuras poéticas, los temas y el sentido de los viejos sones para obtener la facultad de crear nuevos versos y nuevos sones que pudieran evocar el mundo actual y sus imágenes. Es así que el son jarocho comienza a reinventarse: a partir de la improvisación de versos en el fandango -siempre dentro de los límites de la estructura poética y semántica de cada son-, llamados "versos de nueva creación"; pero también en el surgimiento de nuevos sones en el seno de los grupos conformados, considerados "sones de autoría" (HERNÁNDEZ, 2016). 
Esos fandangos campesinos de antaño eran espacios comunitarios de expresión festiva en donde se reforzaban lazos sociales de todo tipo, ya fuera para forjar relaciones amistosas, formar parejas o integrar a los jóvenes y a los mayores en el aprendizaje de los elementos del fandango, a través de la observación, imitación y la práctica. Este proceso de enseñanza-aprendizaje de generación en generación en las comunidades rurales había decaído al paso del tiempo por diversos motivos: la migración de las generaciones más jóvenes a los centros urbanos en busca de oportunidades laborales o por estudio, lo que provocó una brecha generacional entre los practicantes del son; la popularización de las radios y tocadiscos en las comunidades rurales, lo que condujo al declive del son jarocho en comparación con otros géneros musicales urbanos que estaban en boga en la época (como la salsa o la cumbia); la pérdida de vigencia de las prácticas comunitarias, como los fandangos, frente a la irrupción de prácticas económicas de orden capitalista, etc. Estos y otros motivos crearon una realidad compleja para los fandangos, que fueron cada vez menos frecuentes y sin una generación de relevo para continuar la práctica.

La intención de los pioneros del Movimiento jaranero era recordar, junto con los viejos soneros, esos conocimientos en semiolvido y encontrar formas didácticas de transmitir ese saber a los niños y jóvenes de las comunidades, al principio, y luego a los que tenían interés en las ciudades, e incitar entre la población el viejo entusiasmo por los fandangos, que son los espacios de aprendizaje por excelencia. Con ese propósito surgen desde el esfuerzo ciudadano y con el financiamiento de diversas instituciones culturales, los campamentos de son jarocho y los talleres de zapateado, décimas, laudería y son jarocho que, además de enseñar las características técnicas, buscaban retornar la médula comunitaria del fandango.

\section{FANDANGOS JAROCHOS COMO PATRIMONIO}

En la jaula de mi pecho una paloma encerré como no era de provecho le abrí la jaula y se fue para los campos derecho.

-El pájaro Cú, son jarocho. 
En marzo de 2010, el gobierno del estado de Veracruz, presidido por el gobernador del estado, Fidel Herrera Beltrán, manifestó en diversos medios de comunicación que buscaría promover ante la Organización de las Naciones Unidas para la Educación, la Ciencia y la Cultura (UNESCO) el son y el fandango jarochos para formar parte de la Lista Representativa de Patrimonio Cultural Inmaterial de la Humanidad, tal como lo hiciera en 2009 con la ceremonia ritual de los voladores de Papantla. Pero no fue sino hasta 2013 que a través de la Secretaría de Turismo, Cultura (Sectur) del Estado de Veracruz, se anunció la integración de un equipo promotor del son jarocho para la salvaguarda del género musical y su fiesta comunitaria, el fandango. En boletín de prensa del 13 de mayo de 2013, la Sectur recalcó que dicho equipo contaría con el respaldo del gobierno del estado para "emprender una gran campaña que lo enaltezca, reconozca y posicione en México y el mundo" (SECTUR, 2013, p.1). Para ello, se buscaba promover la inscripción del son jarocho como Patrimonio Cultural Inmaterial de la Humanidad, generar conciencia de la importancia del son jarocho y la elaboración de medidas para protegerlo y promoverlo.

En esa misma administración, la Sectur apostó por el rescate y la preservación en bienes, tradiciones, arte y acervos históricos, con la finalidad de colocar al estado de Veracruz como un destino turístico para nacionales y extranjeros. El turismo cultural es más rentable en sitios de prestigio internacional, como aquellos que cuentan con el galardón de la UNESCO, lo que garantiza "la competitividad de los destinos" (SECTUR, 2015, p.1). Por ello no es difícil imaginar que detrás del nombramiento de la UNESCO como patrimonio, el gobierno del estado de Veracruz buscaba colocar en el son y el fandango jarocho las medallas de mérito de la organización internacional para su aprovechamiento comercial a través del turismo estatal. Se trataba de una política cultural de corte neoliberal, en el que la cultura popular era orientada hacia el mercado. En términos neoliberales, la cultura funciona como un bien mercantil al que pueden atribuírsele valores simbólicos agregados como los tributos de "tradicional”, "popular", "antiguo" para la generación de lógicas empresariales sobre el patrimonio cultural (ÁVILA, 2008).

No obstante, desde que la intención del gobierno estatal fue evidenciada, numerosas voces soneras se opusieron a la iniciativa, previendo la intención de lucro por parte del sector turístico y la demostrada injerencia de la administración gubernamental respecto a las prácticas tradicionales, como en el caso de las festividades de Tlacotalpan, ciudad declarada Patrimonio Cultural de la 
Humanidad por la UNESCO en 1998. "Antes que de la humanidad, el son es patrimonio de la comunidad jarocha, y que nos pregunten" (WHALEY, 2014, p.1), fueron las palabras de Samuel Aguilera en el Segundo Encuentro del Son Jarocho (2014), lo que refleja una postura de oposición a la apropiación institucional, y que ejemplifica cómo sus practicantes han luchado por reivindicar su protagonismo en la salvaguarda del son y el fandango.

El Movimiento jaranero debe entenderse como un movimiento contracultural, que surge como rechazo a la práctica dominante de folclorización que funcionó bajo el beneplácito y patrocinio del Estado. Si bien su postura de resistencia precisó de las alianzas que estableció con las instituciones culturales de gobierno, el precepto del Movimiento fue el de otorgar el protagonismo de la práctica en manos de sus detentores, y reconstruir el entramado social que se desarrolla alrededor del fandango como espacio de la comunidad. El rechazo al nombramiento de la UNESCO proviene del peligro que representa institucionalizar el mecanismo de salvaguarda en menoscabo de las labores independientes de los practicantes y promotores culturales que lo han revitalizado.

El Movimiento jaranero actuó como un proyecto de salvaguarda del son y el fandango jarochos con consecuencias muy variadas, desde el rescate de la lírica de sones antiguos, la revivificación de fandangos tanto urbanos como rurales, la creación de nuevos sones, la invención de nuevos versos para los sones antiguos -inclusive con la innovación de la versada de perspectiva femenina-, la inserción de nuevos instrumentos en el son jarocho, la enseñanza formal del son jarocho a través de talleres, cursos y seminarios, la proliferación de grupos de son, la fusión del son jarocho con otros géneros musicales, la relativa uniformización de la afinación por cuatro, el surgimiento de practicantes de son y fandangos jarochos en el extranjero, la posibilidad de hacer del son jarocho un medio de subsistencia, etc.

Con todo su recorrido a lo largo de estas cuatro décadas, las transformaciones musicales, comportamentales, instrumentales, etc., el son jarocho y los fandangos demuestran ser actualmente una práctica viva que sigue diversificándose en múltiples contextos. Como práctica viva, no corre peligro de desaparecer, sino de ser transformada por sus practicantes. Son sus practicantes, entonces, quienes han determinado la ruta por la que el género musical y la fiesta se mueven, y son su practicantes quienes reivindican el poder de la toma de decisiones respecto a la tradición, y no las instituciones, en un ejercicio vertical de poder. La evasión del nombramiento como 
patrimonio pretende evitar la formación de un canon formal, institucionalizado, que excluya a las manifestaciones que no se apeguen a las características denominadas.

Ahora bien, la UNESCO caracteriza el patrimonio cultural inmaterial como tradicional, contemporáneo y viviente aun mismo tiempo; integrador, representativo y basado en la comunidad. Respecto a esta última cualidad afirma:

El patrimonio cultural inmaterial sólo puede serlo si es reconocido como tal por las comunidades, grupos o individuos que lo crean, mantienen y transmiten. Sin este reconocimiento, nadie puede decidir por ellos que una expresión o un uso determinado forma parte de su patrimonio (UNESCO, 2003).

En el caso del fandango y su música, sus practicantes sí reconocen su cualidad como patrimonio cultural inmaterial, con la salvedad de que no desean nombramientos oficiales ni la institucionalización de la tradición que ellos mismos han logrado revindicar y revivificar. Los soneros y fandangueros se han hecho oír y una vez más se han posicionado para oponer resistencia a la injerencia estatal en materia de patrimonialización cultural. El panorama ideal en la construcción democrática de políticas culturales no puede ser otro sino la participación horizontal de los distintos entes involucrados en su creación. Los intereses de las instituciones que el Estado gestiona no deben sobreponerse a los intereses de los practicantes del bien cultural.

La labor del Movimiento jaranero no fue conservar la tradición, sino continuarla, y en su hilo de acción no había más alternativa que el cambio. Como resultado de ese movimiento en pro de continuar la tradición han surgido todas aquellas variaciones al fandango campesino de las primeras décadas del siglo XX, pasando desde la vuelta a lo folclórico, atravesando fandangos urbanos y aterrizando en los escenarios, con géneros híbridos de son jarocho y ritmos modernos.

Respecto a la representación del son jarocho como espectáculo en los escenarios en detrimento de su función comunitaria en el fandango, esta divergencia en el recorrido del Movimiento es fácil de comprobar, pero no es una aseveración que se pueda generalizar. Actualmente existen numerosos colectivos que combinan el escenario como actividad profesional y de sustento económico y que también se dedican a la enseñanza del son jarocho y organización 
de fandangos en diversos lugares. Tan sólo por citar algunos se pueden nombrar a Son Barrio Abajo, de Tlacotalpan; Jardín Kojima, de Otatitlán; La Casa de Nadie, de Xalapa; Los Parientes de Playa Vicente, que trabajan en varias comunidades de Veracruz y en la Ciudad de México; el Centro de Documentación del Son Jarocho, una iniciativa de la agrupación Los Cojolites en Jáltipan, Veracruz, que además de realizar talleres de son jarocho para niños y jóvenes y seminarios de estudio del son, también alberga un acervo de documentos, videos, fotos y obra plástica de la cultura jarocha.

El Movimiento jaranero no es el mismo que el de hace cuarenta años. Su quehacer continúa en manos de otra generación de practicantes, y aunque sus métodos no pueden ni serán los mismos, la pretensión de revitalizar el son y el fandango continúa. Han surgido nuevos desafíos a ser enfrentados, nuevas latitudes de donde pueden provenir los jaraneros, incluso nuevas manifestaciones en las que el son jarocho abreva. A pesar de las polémicas y opiniones diversificadas respecto a las divergencias que se han gestado a partir de "lo tradicional", es decir, la usanza antigua, el son jarocho alcanza nuevos horizontes, se enriquece, se nutre de lo propio y de lo ajeno, es abrazado por cada vez más entusiastas y desemboca en escenarios y tarimas de las urbes y los pueblos. Lo que empezó hace 40 años continúa en movimiento y nadie lo detiene.

\section{REFERÊNCIAS}

ALCÁNTARA, A. Del agua, los versos y la poesía. La manta y la raya, 6, 2017.

ÁVILA, H. Políticas Culturales en el Marco de la Democratización: interfaces socioestatales en el Movimiento jaranero de Veracruz, 1979-2006. Tesis de doctorado. Xalapa: CIESAS, 2008.

CARDONA, I.; RINAUDO, C. Son jarocho entre México y Estados Unidos: definición "afro" de una práctica transnacional. Desacatos, n. 53, enero-abril, 2017, pp. 20-37. Distrito Federal: Centro de Investigaciones y Estudios Superiores en Antropología Social.

FANDANGO, buscando al Mono Blanco. Dirección: Ricardo Braojos. Los Cenzontles Mexican Arts Center, 2006. Estados Unidos-México. Video color (66 min). 
FERRERO, C. A viola no fandango de Iguape e Cananéia. Enciclopédia Caiçara. Volume V. Festas, Lendas e Mitos Caiçara. São Paulo: HUCITEC-NUPAUB-CEC/USP, 2006.

FIGUEROA, R. Son Jarocho. Guía histórico-musical. Xalapa: CONACULTA-FONCA, 2007.

FORMATO SIETE. Juan Meléndez de la Cruz, guardián del son, presentará su libro en Realia. Formato Siete, 2017. Disponible en <http://formato7.com/2017/06/25/juan-melendez-de-la-cruzguardian-del-son-presentara-su-libro-en-realia/> Acceso en: 31/12/2017.

GARCÍA, A. Fandango. El ritual del mundo jarocho a través de los siglos. México: CONACULTA-IVEC, 2006.

GOTTFRIED, J. Una puerta cibernética al fandango como fiesta. En SEVILLA, A. El fandango y sus variantes. México: INAH, 2013.

GUTIÉRREZ, G. La tradición en el tercer milenio. Ponencia en El fandango jarocho, un mundo de vida. Reflexión y diálogo intercultural e intergeneracional con representantes del fandango, 2009. Disponible en: <https://mundodevida.wordpress.com/category/ponencias/> Acceso en: 07/01/2018.

HERNÁNDEZ, M. Mujeres divinas y profanas: La bruja, la llorona y la sirena en el imaginario social del Movimiento jaranero contemporáneo. Tesis. México: Centro de Estudios de la Cultura y la Comunicación, Universidad Veracruzana, 2016.

KHOL, R. Declaraciones del son. El requinto jarocho en la creación del conocimiento sociomusical. Veracruz: Editora de Gobierno del Estado de Veracruz, 2007.

MELÉNDEZ, J. Dos actas de defunción... y se mueve. La manta y la raya, 1, p.p. 12-16, 2016.

NGOU-MVE, N. El África bantú en la colonización de México (1595-1640). Madrid: Consejo Superior de Investigaciones Científicas, 1994.

NÚÑEZ, J. Los huapangos. Mexican Folkways. Vol. VII (4) México, 1932.

OLIVARES, J. Serán 12 horas de fandango en el festival Guillermo Cházaro Lagos. La Jornada, 29 de noviembre de $2016 . \quad$ Disponible en: <http://www.jornada.unam.mx/2016/11/29/espectaculos/a09n1esp > Acceso en: 04/01/2018 
PEREZ, R. Estampas de nacionalismo popular mexicano. México: CIESAS, 1994.

PÉREZ, R. La fruta madura (el fandango sotaventino del XIX a la Revolución). Secuencia. Revista de Historia y Ciencias Sociales, 19, p.p. 43-60, 1991.

PITRE, E. Prácticas musicales en contextos latinoamericanos: esbozo de la música del fandango jarocho de Veracruz en México (Parte 1). Investigación pos-doctoral. Ciudad de México: UNAM, 2016.

SANCHEZ, R. Diferenciasformales entre la lírica de los sones huastecos y la de los sones jarochos. Revista de Literaturas Populares, 2 (1), enero-junio, 2002.

SECTUR. Busca Veracruz que el son jarocho sea Patrimonio Cultural Inmaterial de la Humanidad. Sectur (Boletín de prensa), 2013. Disponible en: $<$ http://jarochelo.com/noticia/proyecto-de-difusion-y-salvaguarda-del-son-jarocho-y-la-fiestacomunitaria-del-fandango/>Acceso en: 14/01/2018.

SECTUR. Promueve y preserva Veracruz riqueza cultural. Sectur. Radio identidad, 2015. Disponible en: <http://radioidentidad.com.mx/promueve-y-preserva-veracruz-riqueza-cultural-

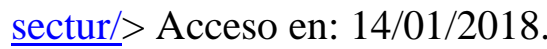

SEVILLA, A. El fandango ayer y hoy. El fandango y sus variantes. México: Instituto Nacional de Antropología e Historia, 2013.

SONEROS del Tesechoacán. El Movimiento del Son Jarocho. 2010. Disponible en: <http://sonerosdeltesechoacan.blogspot.com.br/2010/11/el-movimiento-del-sonjarocho_16.html> Acceso en: 06/01/2018.

STANFORD, T. EI son mexicano. México: Secretaría de Educación Pública, 1984.

UNESCO. Convención para la Salvaguardia del Patrimonio Cultural Inmaterial. 2003. Disponible en: $\quad$ http://portal.unesco.org/es/ev.php-

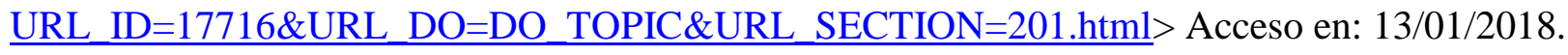


WHALEY, J. El son jarocho no debe ser declarado patrimonio cultural de la humanidad, coinciden expertos. La Jornada, enero de $2014 . \quad$ Disponible en: $<$ http://www.jornada.unam.mx/2014/01/26/espectaculos/a09n1esp > Acceso en: 14/01/2018.

Recebido em: 21/11/2018

Aprovado em: 13/08/2019

Publicado em: 09/10/2019 